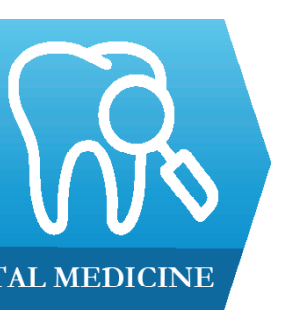

DENTAL MEDICINE

\title{
Evidence based management guidelines in dentistry during the COVID-19 pandemic - a review of the literature
}

Kanamarlapudi Venkata Saikiran ${ }^{1}$, Putta Sai Sahiti ${ }^{2}$, Somisetty Venkata Mahalakshmi Mounika ${ }^{3}$, Sainath Reddy Elicherla ${ }^{4}$, Raichurkar Hemanth Kumar ${ }^{1}$, Gonegandla Giriraj Sandeep ${ }^{5}$

1) Department of Pediatric and Preventive Dentistry, SVS Institute of Dental Sciences, Mahabubnagar, Telangana, India

2) Private dental practice, The dental specialists, Hyderabad, Telangana, India.

3) Department of Oral Medicine and Radiology, Narayana Dental College and Hospital, Nellore, Andhra Pradesh, India

4) Department of Pediatric and Preventive Dentistry, Narayana Dental College and Hospital, Nellore, Andhra Pradesh, India

5) Department of Oral and Maxillofacial Surgery, SVS Institute of Dental Sciences, Mahabubnagar, Telangana, India

DOI: $10.15386 / \mathrm{mpr}-1980$

Manuscript received: 23.11 .2020

Received in revised form: 14.01.2021

Accepted: 18.02.2021

Address for correspondence:

saikiran4u2008@gmail.com

This work is licensed under a Creative Commons Attribution-NonCommercialNoDerivatives 4.0 International License

\begin{abstract}
The present COVID-19 pandemic presents a high risk of transmission. Several infection control procedures have been employed to alleviate the further spread of this disease. The dental practice could be a potential risk factor for the transmission of this virus, which has a potential for aerosol generation. For a successful dental practice, effective infection control guidelines have to be established using relevant scientific research. In this perspective, the present article focused on current systematic reviews with evidence based effective treatment protocols during this pandemic.
\end{abstract}

Keywords: COVID- 19, dentistry, infection control

\section{Introduction}

SARS-CoV-2, which causes COVID-19, spreads principally through respiratory droplets and aerosol with direct or indirect contact [1]. Till this date, due to its close contact, disinfection of air in communities is not acknowledged adequately in reducing further viral transmission. Latest evidence supports that ACE2+ epithelial cell in the salivary glands to be one of the principal targets for SARS coronavirus infection [2]. Thus, it can be predicted that this novel virus is capable of transmitting through dental setting due to close contact with patients' oral cavity and repeated exposure to body fluids like saliva, blood and respiratory tract secretions.

The usage of rotatory instruments such as high-speed handpiece, ultrasonic scalers generate large quantities of aerosols from the patients' oral cavity [3]. However, the pandemic is still in progress; the demand for dental treatment decreased only by $38 \%$, which clearly states the necessity to address the emergency dental care during this pandemic [4]. To continue the health care services, it is always mandatory to proceed with proper precautions to avoid cross-contamination. Hence, this article summarizes the various safety measures with evidence in the existing literature.

\section{Recommendations for infection control and prevention in dental setup}

Routine protective measures in dental setup might not be effective during this pandemic. Dentists and personal staff should take extreme caution to avoid mucosal contact with their facial surfaces, including nose, eyes and mouth $[3,5]$. Hence, proper hand hygiene protocols are mandatory before, during, and after dental practice. Personal protective equipment like masks, face shields, protective eyewear, full body coveralls, surgical hand gloves, head caps, and shoe covers are crucial to avoid cross infections [6]. 


\section{General recommendations}

Not every patient referred to the dental clinic claims to be affected because of the long incubation period of the virus between 2-14 days $[7,8]$. Hence, considering every patient as a potential asymptomatic COVID-19 carrier meticulous screening has to be performed. To achieve this, a proper protocol should be followed to avoid infections. A four-step protocol has been formulated for ease:

A: Assess the patient through tele screening.

B: Build strict pre-procedural steps.

C: Care for both dentists as well as patients to construct a comprehensive treatment plan with minimal operating procedures that minimize cross infections.

\section{D: Disinfection.}

\section{A. Assess the patient through tele screening}

Telehealth enables patients in real-time for receiving health care instructions. Recently, a systematic review stated that telemedicine has the potential to prevent direct physical contact, thereby providing continuous care to the patients and thus decreasing morbidity and mortality during this pandemic [9]. On the other hand, telecommunication can be helpful in screening the patient before the dental visit to minimize the risk of direct transmission from person to person. During this tele screening, dental team should enquire the patients for any COVID -19 symptoms, recent travel history to disease epicenters and need for a dental appointment, any history of family members being affected with COVID19. If there are any suspected symptoms of COVID-19, treatment has to be deferred for at least one month [6]. Once the patient is asymptomatic, the appointment has to be scheduled with delivering proper personal instructions during the dental visit.

\section{B. Build up proper pre-procedural steps}

The dental team should advise the patients to wear the mouth mask and limit the accompanying persons during the dental visit. Pre-check triages to measure and record the body temperature using a noncontact forehead thermometer or infrared temperature sensors and measuring oxygen saturation level should be implemented if the temperature crosses, $100.4^{\circ} \mathrm{F}$ (or $38^{\circ} \mathrm{C}$ ) dental treatments for patients has to be postponed for at least $2-3$ weeks $[1,2,10]$. Pulse oximetry device is commonly used in health care setup for the evaluation of oxygen saturation and pulse rate of the patients [11]. Low saturation levels (50\%-80\%) indicate a hypoxic condition which determines possible critical infection with SARS-COV-2; in such conditions dental procedures are contraindicated or should be deferred $[12,13]$. However, due to lack of proper evidence to support this pulse oximeter in diagnosing this COVID- 19, the dentist should not rely on this device alone.
After the initial screening, the patients are instructed to dispose the mask safely and perform hand hygiene with alcohol-based hand rub or with soap and water. Prolonged contact to water and chemical agents induces epidermal barrier disruption, which leads to impairment of keratinocytes, thereby, a subsequent release of proinflammatory cytokines leads to activation of the skin immune system [14]. WHO recommends hand hygiene thoroughly (including fingernails, interdigital web spaces, wrists) for at least 20 seconds, using lukewarm water and soap [15]. As coronavirus is an enveloped RNA virus, soap/sanitizer tends to damage the envelope and reduces its virulence [16]. Alcohol-based hand sanitizers $(60 \%$ alcohol), could be an effective alternative [17]. This should be followed by patients' comprehensive medical history and COVID-19 pre-screening questionnaire.

\section{Preprocedural mouth rinse}

Aerosolized microorganisms persist suspended in the dental office environment up to 4 hours after the procedure, thus raising the chances of infection [18]. The oral cavity has high viral loads in the oropharynx of the infected patient, therefore unwaveringly associated with the evolutionary process of SARS-CoV-2. Many chemical agents have been used as mouth rinses. Among these agents, chlorhexidine (CHX), cetylpyridinium chloride (CPC), and essential oils (EO) have antimicrobial properties $[19,20,21]$. However, chlorhexidine is not efficient in the SARS-CoV-2, the use of mouth rinses and/or with local nasal applications that contain $\beta$ - cyclodextrins (CDs) collective with flavonoids agents, such as Citrox, might provide an adjunctive to reduce the viral load of saliva and nasopharyngeal microbiota. SARS-CoV-2 is susceptible to oxidation, hence mouth rinses comprising oxidative agents such as amphiphilic CDs, reduce the salivary load of oral microbes. Before irreversibly inactivating them, the modified sugar molecules attract viruses to disrupt their outer shell [22]. Apart from oxidative potential, flavonoids such as coronaviral chymotrypsin-like protease inhibitors have a decisive role for coronaviral duplication and also have complementary functions for inhibition of host innate immune responses and should be beneficial to combat COVID-19 [23]. Hence, pre procedural oral rinse has gained popularity to minimize risk of contamination. Recent studies on mouth rinses stated that SARS-CoV-2 virus was wholly inactivated by $0.2 \%$ of povidone-iodine at a contact time of 30 seconds and gargle for additional 30 seconds are suggested in the throat and spit after 1 minute $[24,25]$. Therefore, preprocedural rinsing with diluted povidone-iodine may be preferred in the clinical settings to decrease the viral load as well as the virulence of aerosolized microorganisms in the patients' oral cavity. However, few studies investigated chlorhexidine and coronaviruses, displaying sensitivity of coronavirus to chlorhexidine only when used in combination with ethanol or cetrimide. In isolation, chlorhexidine has least 
effectiveness against COVID-19 than povidone-iodine in both in vitro studies and studies of disinfection of inanimate surfaces $[26,27]$. Overall, there are incomplete data regarding the action of chlorhexidine against coronaviruses.

\section{Care for the patient and dentist}

Display visual alerts at the entrance of dental setup and in strategic areas (e.g., waiting area or elevators) about respiratory hygiene, cough etiquette, social distancing and disposal of contaminated items in trashcans [28].

\section{Personal protective equipment (PPE)}

Dentists are at higher risk of infection than the general population. The guidelines are given by WHO for infection prevention and control of epidemic- and pandemic-prone acute respiratory infections in health care in 2014 recommends using appropriate PPE as determined by risk assessment. For COVID-19, the WHO 2014, WHO 2020a, WHO 2020b recommend the use of PPE which includes gloves, masks, goggles or face shields, and longsleeved gowns act as a potential barrier, help to prevent direct contact with the contaminated virus and provide adequate resistance to blood and saliva. Therefore, the use of proper PPE during treatment can reduce the chances of physical exposure to the virus. Choosing the appropriate type of PPE and following specific guidance for donning and doffing of PPE as provided by CDC 2020, and WHO 2016 can reduce the risk of self-contamination of $\mathrm{HCW}$ $[29,30,31,32]$.

\section{Eyewear}

The recent systematic review stated that protection of eyes by using goggles or face shield might provide additional benefit for the person to person transmission of the virus [33]. Currently, there is no literature supporting the comparative effectiveness of face shields and goggles for the prevention of virus transmission to health care professionals. Therefore, the Guideline development group assumed equal efficiency in both types of eyewear $[34,35]$.It is also stated that face shield and goggles should not be used together, as this does not offer additional protection and causes more discomfort and fogging, which might affect vision [32]. Several considerations like fogging, comfort and visibility may influence the selection between face shields and goggles.

\section{Gloves}

Dental professionals are recommended to use double gloves over single gloves because double gloves reduce the contamination of hands when removing PPE [32,36]. Surgical gloves are recommended to ensure proper sterile conditions [34]. Nitrile gloves are recommended over the latex gloves because nitrile gloves offer better resistance towards disinfectants, and latex allergies can be prevented [37,38]. Non-powdered gloves are recommended over powdered gloves because this avoids reactions with the alcohol-based handrub [39].

\section{Protective body wear}

The protective clothing should be comfortable, leaktight, breathable for donning and impermeable to liquids, viruses and should possess sufficient quality to protect healthcare patients and personnel from microorganisms, body fluids, and particulate material $[32,40]$. Ideal PPE should contain a label that indicates clearly the standards of the fabric which are evaluated by the laboratory tests, including viral penetration resistance, tensile strength, liquid integrity, and seam strength $[32,41]$. The protective body wears either a disposable gown or a disposable coverall is recommended as part of contact precautions based on Infection control and preventive principles. There is a lack of strong evidence in the literature on the comparative effectiveness of coveralls and gowns in reducing transmission of the virus to health workers [34]. Therefore, it is concluded that coveralls and gowns are equally acceptable forms of body protection and the choice on which to use should be based on availability and health care worker preference. If splashing with blood or other fluids is expected, gowns are not fluid-resistant, a waterproof apron should be worn over the gown [34].

\section{Mask}

Medical masks often called surgical masks, are intended to protect the nasal and oral mucosa from droplets during the aerosol procedures and also to prevent inhalation of various small airborne particles [33,42]. Other types of respiratory masks available for medical purpose are N95, N99, N100, FFP1, FFP2, and FFP3 [43]. Of them, the most commonly used respiratory mask is $\mathrm{N} 95$, as it offers the highest protection against the bacteria and viruses $[44,45]$. In the literature, clinical evidence is inconclusive regarding N95 respirators effectiveness in comparison with surgical masks in acute respiratory illness, laboratory-confirmed respiratory infection, and influenza $[46,47,48]$. Currently, recommendations to protect healthcare workers against COVID-19 for nonaerosol-generating procedures are conflicting. U.S. Centers for Disease Control and Prevention (CDC) and the European Centre for Disease and Prevention (ECDC) recommend the use of N95 respirator for non-aerosolgenerating routine care of patients with COVID-19 $[49,50]$. In contrast, the WHO and Public Health Agency of Canada recommend medical masks [30,51]. As there is no significant data to support the use of N95 over surgical masks, both $\mathrm{N} 95$ and surgical masks offer similar protection when compared with single-layer masks [52]. For aerosol-generating procedures, there is a consensus that N95 respirators provide better protection than medical masks. According to the National Institute for Occupational and safety Health (NIOSH) N95 provides 95\%, N99 provides $99 \%$ efficiency on capturing typical aerosol around $300 \mathrm{~nm}$ size. When there is a limitation for N95 usage, the double surgical mask could be an alternative. Cloth masks should be strictly restricted 
to general use, and it is not suggested for health care professionals.

\section{Footwear}

Even though the quality of evidence was considered very low, a strong recommendation was given to prefer Waterproof boots over closed shoes, because they are easy to clean and disinfect. If boots are not available, Shoe covers are recommended to be used over closed shoes to facilitate decontamination [34].

\section{Disinfection}

SARS-CoV-2 is an enveloped virus which contains a delicate outer lipid envelope that makes it more vulnerable to disinfectants. Whereas on the other hand, non-enveloped viruses such as rotavirus, norovirus and poliovirus are less vulnerable [53]. Though COVID-19 virus exists in an extensive range of $\mathrm{pH}$ values and ambient temperatures, it is predisposed to heat and standard disinfection methods.

Commonly used disinfectants:

- Ethanol 70-90\%

- Chlorine-based products (e.g., hypochlorite) at $0.1 \%(1000 \mathrm{ppm})$ for general environmental disinfection or $0.5 \%$ (5000 ppm) for blood and body fluids large spills

- Hydrogen peroxide $>0.5 \%$

\section{Chlorine-based products}

Hypochlorite-based products comprise liquid (sodium hypochlorite), solid or powdered (calcium hypochlorite) formulations. The mechanism behind these preparations is that it dissolves in water to generate dilute aqueous chlorine solution in which undissociated hypochlorous acid $(\mathrm{HOCl})$ is an active antimicrobial compound. Hypochlorite gets quickly inactivated in the presence of organic material, therefore, regardless of the concentration used, it is necessary to first clean surfaces carefully with soap and water or detergent using mechanical action such as scrubbing or friction. High concentrations of chlorine have the risk of causing corrosion of metal and irritation of skin or mucous membrane, in addition to potential side-effects related to chlorine smell for vulnerable people such as people with asthma [54].

Among various concentrations, $0.05 \%$ hypochlorite is effective against rotavirus. However, higher concentrations of $0.5 \%$ are essential for extremely resistant pathogens in the healthcare setting, such as Candida auris and Clostridioides difficile [55,56]. The recommendation of $0.1 \%$ in the perspective of COVID-19 is a conventional concentration that will deactivate the majority of other pathogens. Nevertheless, for blood and body fluids large spills (i.e. more than about $10 \mathrm{~mL}$ ) a concentration of $0.5 \%(5000 \mathrm{ppm})$ is suggested [54].

\section{HEPA filters}

WHO is considering "airborne precautions" for health care professionals as SARS-CoV-2 remains viable in aerosols for several hours [57]. The uttermost concentration of SARS-CoV-2 aerosols is of two diverse size ranges, one in the submicron region with aerodynamic diameter governing between 0.25 and $1.0 \mu \mathrm{m}$, and the other peak in super micron range with a diameter larger than $2.5 \mu \mathrm{m}$ [58]. Such aerosols in this size range can be commendably removed by air purifiers. High-efficiency particulate air filters (HEPA) count for about $95 \%$ efficiency for particles filtration to remove such virusladen aerosols varying diameter between 0.25 and 1.0 $\mu \mathrm{m}$ and approximately $100 \%$ for diameter larger than $2.5 \mu \mathrm{m}$ [57]. One of the mechanisms behind air purifiers includes dilution ventilation method, which decreases the concentration of dangerous substances in the air while diluting particulate matter (such as fine dust) or gaseous substances (such as volatile organic compounds) [58,59]. Diluted ventilation commonly used due to its low toxicity, low emission rate, and high effectiveness for gaseous substances [59]. These portable, reasonable, and effective air purifiers might decrease the exposure of healthcare workers to aerosols and ultimately lessen the viral load. It is always crucial to prevent secondary contamination by collecting the filters and disposing of them as medical waste. Air purifiers with disinfection proficiency may be more operative for combating the virus. However, guidelines on infection control in dental office according to ECDC \& CDC suggest standard ventilation rate of $\geq 1.5$ air change/hour for non-COVID-19 patients. A constant 6 air change/hour is recommended in COVID-19 patients during and after the visit [60].

\section{UV light}

Implementation of disinfection protocols could decrease the frequencies of healthcare-associated infections. International Ultraviolet Association states that a dose of $40 \mathrm{~mJ} \cdot \mathrm{cm}^{-2}$ of $254 \mathrm{~nm}$ light could eliminate at least $99.99 \%$ of pathogens [61]. UV lightbased systems are available in three ranges based on the wavelength: UVA (315-400 nm), UVB (280-315 nm) and UVC light $(200-280 \mathrm{~nm})$. The germicidal effects of UVC irradiation effects in cellular damage by photo hydration, photo splitting, photo dimerization, and photocrosslinking, thereby hindering cellular replication [62]. However, $254 \mathrm{~nm}$ may not be the ideal wavelength for diminishing all viruses, and this range could damage the viral deoxyribonucleic acid (DNA) or ribonucleic acid (RNA) which impedes the reproducibility of a virus. Shorter wavelengths, around 207-222 nm are capable enough to damage the proteins on the surface of the virus, which is required to attach on human cells. UVA-treated coronavirus displayed substantial spike protein decrease, increased mitochondrial antiviral-signalling protein and decreased coronavirus induced cell death [63]. The UVlight disinfection system has an obligation that it should be activated in unoccupied rooms, in the absence of health personnel and patient [62]. As there is no literature 
evidence of any damage to materials in the room with the usage of UV-light disinfection, this no-touch system for environmental decontamination could be commendably considered during this pandemic in different hospital settings.

\section{Negative pressure isolation room}

For suspected/confirmed cases of COVID-19 requiring emergency dental treatment, utmost personal protection equipment should be implemented in dental office for dentist and dental personnel. The confirmed individuals can be treated in negative pressure isolation rooms as it reduce the risk of infection via airborne transmission to other persons [64]. Usually these rooms are useful for the patients who necessitate airborne droplet nuclei isolation like measles, varicella zoster and tuberculosis. The room should be equipped with a hand wash basin with 'hands free' operation, self-closing door, attached lavatory and HEPA filtration system with $100 \%$ outside air ventilation [3].

Disposable anti-splash isolation device

To protect the dental team and patients, advanced oral isolation suction device is also necessary to prevent transmission of saliva and blood in the atmosphere. It can be achieved by various intraoral and extraoral isolation devices. Intraoral devices like the IsoLite system have more effective in reducing aerosols than high volume evacuator and rubber dam. Extraoral devices like antisplash isolation devices around the patients head or upper body also reduce aerosols spread in the dental setting. Teichert-Filho $\mathrm{R}$ et al. designed a new device made up of rigid translucent acrylic material which is easily accustomed towards the dental chair to reduce aerosol dispersion in the dental clinic. It also contains negative pressure generating piping system for air filtration. The authors stated that the proposed device could be used in conjunction with standard PPE to reduce transmission risk during COVID-19 [65].

\section{Anti-retraction handpiece}

High-speed dental handpiece generally comprises retraction and anti-retraction mechanisms. Handpiece without anti-retraction valves can aspirate and expel the fluids and debris during the dental procedures. Antiretraction dental handpiece can considerably decrease the backflow of oral bacteria into the handpiece and dental unit tubes. Hence, the handpiece with anti-retractive valves is strongly recommended for cross-infection prevention during COVID-19 [66].

\section{Purification of pipeline water}

In dental unit water lines, a regular rinsing and washing with proper disinfection solution and water are advised. Ideally, rinsing the water line unit for two minutes at the beginning and end of each procedure is recommended during this pandemic. To reduce the risk of contamination, frequent water quality testing can be advisable to meet safe drinking water standard $(<500$
$\mathrm{CFU} / \mathrm{mL})[26]$.

HVAC (Heating, Ventilation, and Air Conditioning) system

Compromised ventilation system increases the transmission of respiratory diseases, especially in confined spaces. The HVAC system is configured to provide air filtering and cooling/ warming and dehumidification. However, the HVAC system retains large droplets but not aerosols whereas HEPA filters can filter particle size of SARS-COV-2 (approx. 70-120mm). Air purifiers with HEPA 14 filter/ higher (filtration efficiency $\geq 99.95 \%$ ) for particles $\geq 0.01 \mathrm{~mm}$ are highly mandatory [67].

\section{Negative ion generators}

These are widely used in air purification for home and industrial purpose. It scatters charged ions that adhere to constituents in the air, such as bacteria or viruses, thereby filtered in the device. In the dental setup the effect of these generators on SARS-CoV-2 is not evident in the literature $[67,68]$.

\section{Ozonators}

These are generally used in indoor air purification where this generates ozone from oxygen which is toxic to bacterial and viruses. Ozone generators possess a negative impact on occupational health at increased concentrations that violate public health standards. Usage of these generators in dental setup does not guarantee the effective removal of SARS-COV-2. [67,68]

\section{Stand-alone HEPA filters}

The stand-alone system's primary difference is that they recirculate the air without mixing with the outdoor air. The use of these devices can be considered especially in the spaces where there is optimum ventilation. However, these systems should be confined to small areas and need to be placed in closer proximity to operating personnel. This stand-alone device can be considered an alternative where HVAC systems cannot recirculate the air [67,69].

In conclusion, it is essential for dental professionals to understand the current situation and must be aware of the current evidence based guidelines of SARS-COV-2 to safeguard the public and continue high standards of dental care and infection control to provide appropriate treatment. The dental professional must be conscious about the spreading modalities and pay attention to the self-protection measures in order to deliver dental services during this pandemic.

\section{References}

1. Ather A, Patel B, Ruparel NB, Diogenes A, Hargreaves KM. Coronavirus disease 19 (COVID-19): implications for clinical dental care. J Endod. 2020;46:584-595.

2. Baghizadeh Fini M. What dentists need to know about COVID-19. Oral Oncol. 2020;105:104741.

3. Ge ZY, Yang LM, Xia JJ, Fu XH, Zhang YZ. Possible 
aerosol transmission of COVID-19 and special precautions in dentistry. J Zhejiang Univ Sci B. 2020;21:361-368.

4. Guo H, Zhou Y, Liu X, Tan J. The impact of the COVID-19 epidemic on the utilization of emergency dental services. J Dent Sci. 2020;15:564-567.

5. Fallahi HR, Keyhan SO, Zandian D, Kim SG, Cheshmi B. Being a front-line dentist during the Covid-19 pandemic: a literature review. Maxillofac Plast Reconstr Surg. 2020;42:12.

6. Alharbi A, Alharbi S, Alqaidi S. Guidelines for dental care provision during the COVID-19 pandemic. Saudi Dent J. 2020;32:181-186.

7. Lauer SA, Grantz KH, Bi Q, Jones FK, Zheng Q, Meredith $\mathrm{HR}$, et al. The incubation period of coronavirus disease 2019 (COVID-19) from publicly reported confirmed cases: estimation and application. Ann Intern Med. 2020;172:577582.

8. Linton NM, Kobayashi T, Yang Y, Hayashi K, Akhmetzhanov AR, Jung SM, et al. Incubation period and other epidemiological characteristics of 2019 novel coronavirus infections with right truncation: a statistical analysis of publicly available case data. J Clin Med. 2020;9:538.

9. Monaghesh E, Hajizadeh A. The role of telehealth during COVID-19 outbreak: a systematic review based on current evidence. BMC Public Health. 2020;20:1193.

10. Peng X, Xu X, Li Y, Cheng L, Zhou X, Ren B. Transmission routes of 2019-nCoV and controls in dental practice. Int $\mathrm{J}$ Oral Sci. 2020;12:9.

11. Starr N, Rebollo D, Asemu YM, Akalu L, Mohammed HA, Menchamo MW, et al. Pulse oximetry in low-resource settings during the COVID-19 pandemic. Lancet Glob Health. 2020;8:e1121-e1122.

12. Jouffroy R, Jost D, Prunet B. Prehospital pulse oximetry: a red flag for early detection of silent hypoxemia in COVID-19 patients. Crit Care. 2020;24:313.

13. Levitan RM. Pulse oximetry as a biomarker for early identification and hospitalization of COVID-19 pneumonia. Acad Emerg Med. 2020;27:785-786.

14. Nguyen HLT, Trujillo-Paez JV, Umehara Y, Yue H, Peng G, Kiatsurayanon C, et al. Role of Antimicrobial Peptides in Skin Barrier Repair in Individuals with Atopic Dermatitis. Int J Mol Sci. 2020;21:7607.

15. Beiu C, Mihai M, Popa L, Cima L, Popescu MN. Frequent Hand Washing for COVID-19 Prevention Can Cause Hand Dermatitis: Management Tips. Cureus. 2020;12:e7506.

16. Alzyood M, Jackson D, Aveyard H, Brooke J. COVID-19 reinforces the importance of handwashing. J Clin Nurs. 2020;29:2760-2761.

17. Golin AP, Choi D, Ghahary A. Hand sanitizers: A review of ingredients, mechanisms of action, modes of delivery, and efficacy against coronaviruses. Am J Infect Control. 2020;48:1062-1067.

18. Veena HR, Mahantesha S, Joseph PA, Patil SR, Patil SH. Dissemination of aerosol and splatter during ultrasonic scaling: a pilot study. J Infect Public Health. 2015;8:260-265.

19. Van Strydonck DA, Slot DE, Van der Velden U, Van der
Weijden F. Effect of a chlorhexidine mouthrinse on plaque, gingival inflammation and staining in gingivitis patients: a systematic review. J Clin Periodontol. 2012;39:1042-1055.

20. Haps S, Slot DE, Berchier CE, Van der Weijden GA. The effect of cetylpyridinium chloride-containing mouth rinses as adjuncts to toothbrushing on plaque and parameters of gingival inflammation: a systematic review. Int J Dent Hyg. 2008;6:290-303.

21. Araujo MWB, Charles CA, Weinstein RB, McGuire JA, Parikh-Das AM, Du Q, et al. Meta-analysis of the effect of an essential oil-containing mouthrinse on gingivitis and plaque. J Am Dent Assoc. 2015;146:610-622.

22. Carrouel F, Viennot S, Ottolenghi L, Gaillard C, Bourgeois D. Nanoparticles as anti-microbial, anti-inflammatory, and remineralizing agents in oral care cosmetics: A review of the current situation. Nanomaterials (Basel). 2020;10:140.

23. Zhang L, Liu Y. Potential interventions for novel coronavirus in China: A systematic review. J Med Virol. 2020;92:479490.

24. Bidra AS, Pelletier JS, Westover JB, Frank S, Brown SM, Tessema B. Comparison of in vitro inactivation of SARS $\mathrm{CoV}-2$ with hydrogen peroxide and povidone-iodine oral antiseptic rinses. J Prosthodont. 2020;29:599-603.

25. Imran E, Khurshid Z, M Al Qadhi AA, A Al-Quraini AA, Tariq K. Preprocedural use of povidone-iodine mouthwash during dental procedures in the COVID-19 pandemic. Eur J Dent. 2020;14(S 01):S182-S184.

26. Li G, Chang B, Li H, Wang R, Li G. Precautions in dentistry against the outbreak of corona virus disease 2019. J Infect Public Health. 2020;13:1805-1810.

27. Parhar HS, Tasche K, Brody RM, Weinstein GS, O'Malley BW Jr, Shanti RM, et al. Topical preparations to reduce SARS-CoV-2 aerosolization in head and neck mucosal surgery. Head Neck. 2020;42:1268-1272.

28. Krithikadatta J, Nawal RR, Amalavathy K, McLean W, Gopikrishna V. Endodontic and dental practice during COVID-19 pandemic: Position statement from the Indian Endodontic Society, Indian Dental Association, and International Federation of Endodontic Associations. Endodontology. 2020;32:55-66.

29. World Health Organization. Infection prevention and control of epidemic-and pandemic-prone acute respiratory infections in health care. 2014. Available from: https://apps.who.int/ iris/bitstream/handle/10665/112656/9789241507134_eng. pdf? sequence $=1$

30. World Health Organization. Rational use of personal protective equipment (PPE) for coronavirus disease (COVID-19): interim guidance. March 2020. Available from: https:/apps.who.int/iris/bitstream/handle/10665/331498/ W H O - 2019 - n Co V-I P C P P E_us e - 2020.2 - en g . pdf? sequence $=1 \&$ isAllowed $=\mathrm{y}$

31. Centers for Disease Control and Prevention. Using Personal Protective Equipment (PPE). Available from: https://www. cdc.gov/coronavirus/2019-ncov/hcp/using-ppe.html

32. Verbeek JH, Rajamaki B, Ijaz S, Sauni R, Toomey E, Blackwood B, et al. Personal protective equipment for preventing highly infectious diseases due to exposure to 
contaminated body fluids in healthcare staff. Cochrane Database Syst Rev. 2020;4:CD011621.

33. Chu DK, Akl EA, Duda S, Solo K, Yaacoub S, Schünemann $\mathrm{HJ}$, et al. Physical distancing, face masks, and eye protection to prevent person-to-person transmission of SARS-CoV-2 and COVID-19: a systematic review and meta-analysis. Lancet. 2020;395:1973-1987.

34. World Health Organization. Personal protective equipment for use in a filovirus disease outbreak: Rapid advice guideline. November 2016. Available from: https://apps.who.int/ iris/bitstream/handle/10665/251426/9789241549721-eng. pdf? sequence $=1$

35. Hersi M, Stevens A, Quach P, Hamel C, Thavorn K, Garritty $\mathrm{C}$, et al. Effectiveness of personal protective equipment for healthcare workers caring for patients with filovirus disease: a rapid review. PLoS One. 2015;10:e140290.

36. Mischke C, Verbeek JH, Saarto A, Lavoie MC, Pahwa M, Ijaz S. Gloves, extra gloves or special types of gloves for preventing percutaneous exposure injuries in healthcare personnel. Cochrane Database Syst Rev. 2014;3:CD009573.

37. Rego A, Roley L. In-use barrier integrity of gloves: latex and nitrile superior to vinyl. Am J Infect Control. 1999;27:405410.

38. Kumar RP. Latex allergy in clinical practice. Indian $\mathbf{J}$ Dermatol. 2012;57:66-70.

39. Kanjirath PP, Coplen AE, Chapman JC, Peters MC, Inglehart MR. Effectiveness of gloves and infection control in dentistry: student and provider perspectives. J Dent Educ. 2009;73:571-580.

40. Kilinc FS. A review of isolation gowns in healthcare: fabric and gown properties. J Eng Fiber Fabr. 2015;10:180-190.

41. Centers for Disease Control and Prevention. Considerations for Selecting Protective Clothing used in Healthcare for Protection against Microorganisms in Blood and Body Fluids. April 2020. Available from: https:/www.cdc.gov/ niosh/npptl/topics/protectiveclothing/default.html

42. Tran K, Cimon K, Severn M, Pessoa-Silva CL, Conly J. Aerosol generating procedures and risk of transmission of acute respiratory infections to healthcare workers: a systematic review. PLoS One. 2012;7:e35797.

43. Agrawal H, Singh S, Gupta N. What All We Should Know About Masks in COVID-19 Pandemic. Indian J Surg. 2020;9:1-2.

44. MacIntyre CR, Wang Q, Seale H, Yang P, Shi W, Gao Z, et al. A randomized clinical trial of three options for N95 respirators and medical masks in health workers. Am J Respir Crit Care Med. 2013;187:960-966.

45. Mostafaei A, Hajebrahimi S, Sadeghi-ghyassi F, Mostafaei H, Abolhasanpour N, Nasseri A, et al. Can Wearing a Face Mask Protect from COVID-19? A Systematic Review. Iran J Med Microbiol. 2020;14:101-107.

46. Smith JD, MacDougall CC, Johnstone J, Copes RA, Schwartz B, Garber GE. Effectiveness of N95 respirators versus surgical masks in protecting health care workers from acute respiratory infection: a systematic review and metaanalysis. CMAJ. 2016;188:567-574.

47. Long $\mathrm{Y}, \mathrm{Hu} \mathrm{T}$, Liu L, Chen R, Guo Q, Yang L, et al.
Effectiveness of N95 respirators versus surgical masks against influenza: A systematic review and meta-analysis. J Evid Based Med. 2020;13:93-101.

48. Loeb M, Dafoe N, Mahony J, John M, Sarabia A, Glavin $\mathrm{V}$, et al. Surgical mask vs N95 respirator for preventing influenza among health care workers: a randomized trial. JAMA. 2009;302:1865-1871.

49. Centers for Disease Control and Prevention (CDC). Interim Infection Prevention and Control Recommendations for Patients with Suspected or Confirmed Coronavirus Disease 2019 (COVID19) pandemic. July 15, 2020. Available from: https://www.cdc.gov/coronavirus/2019-ncov/infectioncontrol/control-recommendations.html

50. European Centre for Disease Prevention and Control. Guidance for wearing and removing personal protective equipment in healthcare settings for the care of patients with suspected or confirmed COVID-19. February 2020. Available from: $\quad$ https://www.ecdc.europa.eu/sites/default/files/ documents/COVID-19-guidance-wearing-and-removingpersonal-protective-equipment-healthcare-settings-updated. pdf (Accessed August 2020).

51. Public Health Agency of Canada (PHAC). Coronavirus disease (COVID-19): For health professionals. August 18, 2020. Available from: https://www.canada.ca/en/publichealth/services/diseases/2019-novel-coronavirus-infection/ health-professionals.html

52. Bartoszko JJ, Farooqi MAM, Alhazzani W, Loeb M. Medical masks vs N95 respirators for preventing COVID-19 in healthcare workers: A systematic review and meta-analysis of randomized trials. Influenza Other Respir Viruses. 2020;14:365-373.

53. Rutala WA, Weber DJ. Best practices for disinfection of noncritical environmental surfaces and equipment in health care facilities: A bundle approach. Am J Infect Control. 2019;47S:A96-A105.

54. CDC and ICAN. Best Practices for Environmental Cleaning in Healthcare Facilities in Resource-Limited Settings. Atlanta, GA: US Department of Health and Human Services, CDC; Cape Town, South Africa: Infection Control Africa Network;2019. Available from: https://www.cdc.gov/hai/ pdfs/resource-limited/environmental-cleaning-RLS-H.pdf

55. Pereira SS, Oliveira HM, Turrini RN, Lacerda RA. Disinfection with sodium hypochlorite in hospital environmental surfaces in the reduction of contamination and infection prevention: a systematic review. Rev Esc Enferm USP. 2015;49:681-688.

56. Köhler AT, Rodloff AC, Labahn M, Reinhardt M, Truyen U, Speck S. Efficacy of sodium hypochlorite against multidrug-resistant Gram-negative bacteria. J Hosp Infect. 2018;100:e40-e46.

57. Zhao B, Liu Y, Chen C. Air purifiers: A supplementary measure to remove airborne SARS-CoV-2. Build Environ. 2020;177:106918.

58. Tang S, Mao Y, Jones RM, Tan Q, Ji JS, Li N, et al. Aerosol transmission of SARS-CoV-2? Evidence, prevention and control. Environ Int. 2020;144:106039.

59. Ham S. Prevention of exposure to and spread of COVID-19 
using air purifiers: challenges and concerns. Epidemiol Health. 2020;42:e2020027.

60. Tysiąc-Mista M, Dubiel A, Brzoza K, Burek M, Pałkiewicz $\mathrm{K}$. Air disinfection procedures in the dental office during the COVID-19 pandemic. Med Pr. 2020; 72(1):39-48.

61. Mackenzie D. Ultraviolet Light Fights New Virus. Engineering (Beijing).2020;6:851-853.

62. Casini B, Tuvo B, Cristina ML, Spagnolo AM, Totaro M, Baggiani A, et al. Evaluation of an Ultraviolet C (UVC) Light-Emitting Device for Disinfection of High Touch Surfaces in Hospital Critical Areas. Int J Environ Res Public Health. 2019;16:3572.

63. Rezaie A, Leite GGS, Melmed GY, Mathur R, VillanuevaMillan MJ, Parodi G, et al. Ultraviolet A light effectively reduces bacteria and viruses including coronavirus. PLoS One. 2020;15:e0236199.

64. Meng L, Hua F, Bian Z. Coronavirus Disease 2019 (COVID-19): Emerging and future challenges for dental and oral medicine. J Dent Res. 2020;99:481-487.

65. Teichert-Filho R, Baldasso CN, Campos MM, Gomes MS.
Protective device to reduce aerosol dispersion in dental clinics during the COVID-19 pandemic. Int Endod J. 2020;53:1588-1597.

66. Checchi V, Bellini P, Bencivenni D, Consolo U. COVID-19 dentistry-related aspects: a literature overview. Int Dent J 2020 (in press).

67. European centre for disease prevention and control. Heating, ventilation and air-conditioning systems in the context of COVID-19: first update. $10^{\text {th }}$ November 2020. Available from: https://www.ecdc.europa.eu/sites/default/files/ documents/Heating-ventilation-air-conditioning-systems-inthe-context-of-COVID-19-first-update.pdf

68. Luengas A, Barona A, Hort C, Gallastegui G, Platel V, Elias A. A review of indoor air treatment technologies. Rev Environ Sci Biotechnol. 2015;14:499-522.

69. Federation of European Heating Ventilation and Air Conditioning Associations (REHVA). COVID-19 Guidance Document [August 2020]. Available from: https://www. rehva.eu/fileadmin/user_upload/REHVA_COVID19_ guidance_document_V3_03082020.pdf 